Insight

\title{
Patch Size and Population Density: the Effect of Immigration Behavior
}

\author{
$\underline{\text { Jeff Bowman }}^{1}, \underline{\text { Naomi Cappuccino }}^{2}$, and Lenore Fahrig $^{2}$
}

ABSTRACT. Many habitat fragmentation experiments make the prediction that animal population density will be positively related to fragment, or patch, size. The mechanism that is supposed to result in this prediction is unclear, but several recent reviews have demonstrated that population density often is negatively related to patch size. Immigration behavior is likely to have an important effect on population density for species that do not show strong edge effects, for species that have low emigration rates, and during short-term habitat fragmentation experiments. We consider the effect that different kinds of immigration behaviors will have on population density and we demonstrate that only a minority of possible scenarios produce positive density vs. patch size relationships. More commonly, these relationships are expected to be negative. Our results demonstrate the importance of considering autecological mechanisms, such as immigration behavior, when developing the predictions that we test in habitat fragmentation or other experiments.

\section{INTRODUCTION}

Debinski and Holt (2000) recently reviewed 13 habitat fragmentation experiments and found that one prediction that "works" only about half of the time is the expectation of lower population density in smaller fragments. Similarly, in a meta-analysis of studies relating patch size to population density, Bender et al. (1998) found that the sign of the relationship was positive and negative in almost equal numbers of species (72 positive and 62 negative relationships). Bowers and Matter (1997) demonstrated a similar result in a review of small-mammal studies.

The origins of the prediction that population density should increase with patch size are unclear. Although the theory of island biogeography is often the starting point for studies of habitat fragmentation, MacArthur and Wilson (1967) did not explicitly address how densities of individual species should vary on islands of different sizes. In fact, the theory assumes that abundances of individual species increase linearly with island area, which would result in densities that are independent of island size. Moreover, if large islands have more species, as MacArthur and Wilson's theory predicts, then density compensation among competing species in a guild would result in lower densities of individual species on larger islands (Schoener 1986; see Connor et al. 2000). Despite the neutral or negative density-area relationships implied by the theory of island biogeography, the theory is occasionally cited as the source of the prediction that density should be lower in smaller habitat fragments (e.g., Foster and Gaines 1991).

Another possible conceptual basis for expecting positive relationships between patch size and density is Root's (1973) resource concentration hypothesis, which predicts that specialist herbivores should have higher densities in large, dense, or pure stands of their host plants. Although none of the authors of the fragmentation experiments reviewed by Debinski and Holt (2000) cited Root (1973), it is nonetheless possible that the predictions of the resource concentration hypothesis have become part of conservation ecology "folklore." We suspect that Root's hypothesis and island biogeography theory are frequently the implicit sources of expectations about how density should vary with fragment size. Our suspicions are supported by authors who do not explicitly state the origins of their predictions, but express surprise at finding a negative relationship (e.g., Benitez-Malvido 1998, Dooley and Bowers 1998). Only a small proportion of authors develop their own hypotheses about how patch size should affect density, deriving mechanistic predictions based on the details of how their study organisms disperse to habitat fragments (e.g., Holt et al. 1995, Yao et al.

${ }^{1}$ Ontario Ministry of Natural Resources; ${ }^{2}$ Carleton University 
1999). As we shall demonstrate, the details of movement and patch immigration differ greatly from one organism to the next, contributing to the appropriate prediction for the relationship between patch size and population density.

Immigration behavior can have a positive or negative effect, or it can have no effect, on the relationship between population density and patch size. Although we generally expect an increase in the total number of immigrants per patch with increasing patch size, we suggest that many behaviors will result in a negative relationship between the number of immigrants per unit area and patch size. All else being equal, this should result in a negative relationship between patch size and population density. We recognize that all else is not always equal and that other processes affecting density - birth, death, and emigration - could differ with patch size as well. This leaves the difficult situation of four processes potentially varying at once. However, simulation and empirical studies have shown that immigration increases the size of local populations (Connor et al. 1983, Rey and Strong 1983, Fahrig and Merriam 1985, Fahrig and Paloheimo 1988, Venier and Fahrig 1996), and it is frequently suggested that immigration has important effects on population density in habitat fragments. Immigration is especially important for population density in shortterm experiments of the sort reviewed by Debinski and Holt (2000) because the effect of individuals dispersing from an experimentally created matrix into habitat patches is probably strongest during the few years following habitat removal. Thus, we focus on immigration behavior as a first step in developing predictions about how processes affect population density in differently sized patches. Our results apply to situations in which immigration is thought to be the dominant process.

Table 1. Expected relationship between population density and patch size based on differences in patch immigration behavior.

Orientation type

A) No searching

B) Random searching, no orientation toward patches

C) Orientation toward patches proportional to patch size (linear dimension or area)

D) Orientation toward patches increases disproportionately with patch size (linear dimension or area)
1) Ground or near-ground movement

2) Aerial movement

No relationship

(immigration proportional to patch area)

dimension of patch; linear

dimension/patch area decreases with

increasing patch area)

Negative

(immigration only slightly larger for larger patches, so density decreases with increasing patch area)

Negative

(area of attraction is proportional to linear dimension; linear dimension/patch area decreases with increasing patch area)

Negative to positive (switch from negative to positive occurs when area of attraction is a simple multiple of patch area)
Negative

(immigration only slightly larger for larger patches, so density decreases with increasing patch area)

No relationship (area of attraction is proportional to patch area)

Positive 
Fig. 1. Expected relationship between density and patch size for species that move at or near ground level (column 1 in Table 1). Panel letters correspond to row letters in Table 1.
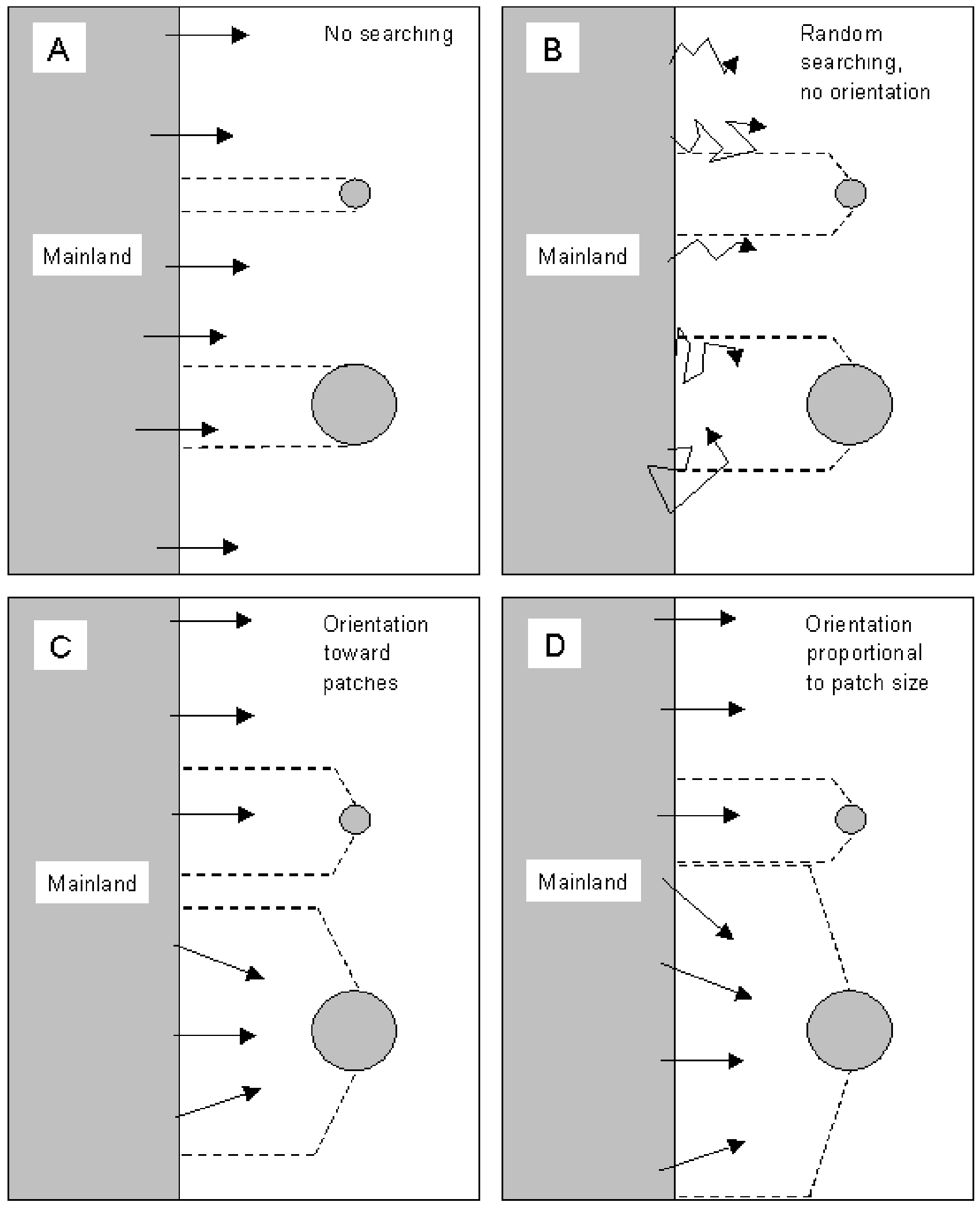
Fig. 2. Expected relationship between density and patch size for aerial dispersers (column 2 in Table 1). Panel letters correspond to row letters in Table 1.
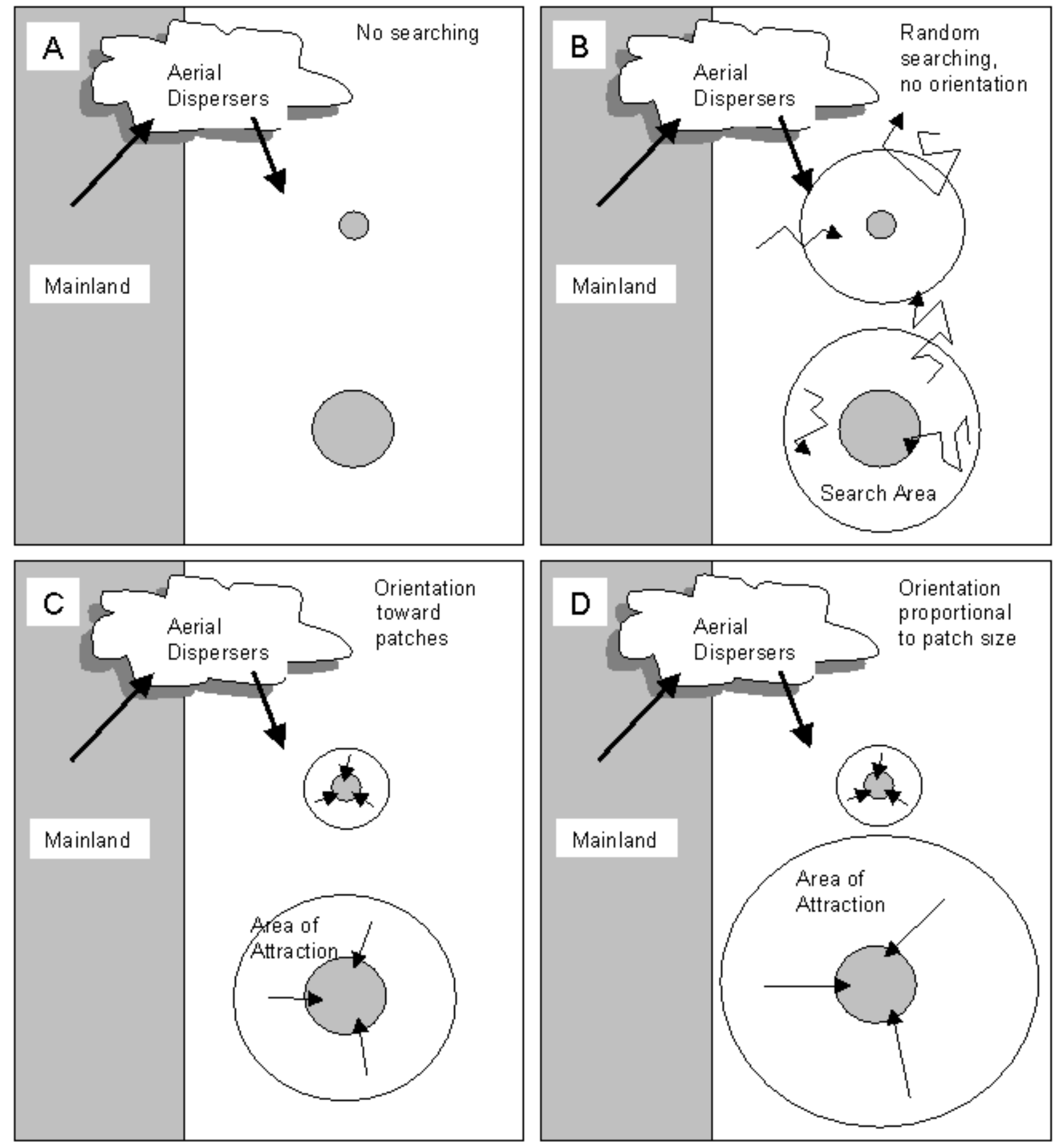

\section{A CATEGORIZATION OF IMMIGRATION BEHAVIORS}

We present a simple categorization of immigration behaviors (Table 1, Figs. 1 and 2), considering three factors: (1) dispersal is at or near ground level vs. dispersal is aerial; (2) dispersers engage in searching, or not; and (3) dispersers are able to orient toward 
their preferred habitat from some distance, or not. The combination of these factors determines whether the number of immigrants per unit area decreases, is constant, or increases in relation to patch size.

Species that disperse at ground level are likely to show negative relationships between patch size and immigration per unit area. This is because the probability of intercepting a patch will be proportional to the linear dimension of the patch rather than the area of the patch. Because patch area increases exponentially with patch linear dimension, the number of immigrants per unit area decreases with increasing patch size. All else being equal, this should result in a negative relationship between patch size and population density (Fig. 1).

For example, seeds of yellow birch Betula lenta blow across packed snow and are deposited in depressions caused by uprooted trees, which constitute suitable sites for germination (Matlack 1989). The number of seeds intercepting a depression should be proportional to the perimeter of the depression (Fig. 1A), which increases as a linear function of the radius $(2 \pi r$ for a circular depression). Abundance of seeds should therefore be higher in larger depressions. However, because the area of the patch increases as the square of the linear dimensions $\left(\pi r^{2}\right)$, we would expect density of seeds to decline as depression size increases.

Small animals, such as mites and spiderlings, may disperse by launching themselves into a convective updraft and entering the "aerial plankton" (Richter 1970). The behavior and orientation abilities of aerial plankters descending from the atmosphere is not well understood, although there is evidence that they may be "scrubbed" from the atmosphere by rain (Russell 1999). Aerial plankters with little control over their ultimate destination, such as seeds or fungal spores, would be deposited onto habitat patches in direct proportion to patch area, as in Fig. 2A. Those failing to land in a patch might die if the matrix is a hostile environment. For such organisms, we would expect no relationship between patch size and the number of immigrants per unit area. Thus, all else being equal, we would expect no relationship between patch size and populaton density-the "random-sample hypothesis" (e.g., Andrén 1994).

Large insects, such as the spruce budworm, may also disperse in the aerial plankton, and may similarly be deposited by weather events such as thunderstorm downdrafts (Greenbank et al. 1980). However, unlike mites and spiderlings, larger insects landing outside a patch are unlikely to die immediately; instead, they would continue searching, some randomly (Fig. 2B). For example, after its daily egg-laying bout, a female cabbage butterfly (Pieris rapae) disperses at an altitude of about $100 \mathrm{~m}$, for a distance of about $450 \mathrm{~m}$, in a random direction. The following day she randomly searches at ground level for host plants. Because of the ground-level search, this dispersal behavior results in a negative relationship between host patch size and density of cabbage butterfly eggs and larvae (Fahrig and Paloheimo 1987); see Fig. 2B. Long-jawed orb-weaving spiders (Tetragnatha elongata) discover woodland patches through random unoriented movement (Gillespie 1987), as in Fig. 2B; all else being equal, we would predict a negative relationship between patch size and population density for this species.

Other insects that disperse in the aerial plankton make the final approach to patches low to the ground, orienting toward patches using some interplay of visual and olfactory cues (Prokopy and Owens 1983). Those for which vision dominates, such as the apple maggot fly Rhagoletis pomonella, which is attracted to silhouettes of host trees (Moericke et al. 1975), would find patches in proportion to their linear dimensions, resulting in lower densities in larger patches. Insects that locate their resources primarily by olfaction, such as the cabbage fly (Erioischia brassicae; Hawkes 1974), might be expected to find patches in direct proportion to their area. Density of such species would show no relationship to patch size.

Experiments in which forest is fragmented by clearcutting often yield negative density relationships as survivors crowd into the remaining forest (e.g., Bierregaard et al. 1992, Hagan et al. 1996, Schmiegelow et al. 1997). As is the case for aerial plankters deposited at random points on the landscape, survivors begin their search for a habitat fragment from random points in the clearcut matrix. Depending on their orientation behavior, predicted relationships between density and the size of these fragments may range from negative to positive (Figs. $2 \mathrm{~B}, \mathrm{C}$, or D).

The predictions also depend on the scale of the experiments relative to the distance at which an animal can orient. For example, if the patches in an experiment are several hectares in area, an animal with a detection distance of a few meters will correspond more closely to the random-sample model. The predicted relationship between density and patch size 
also depends on the distance of the patches from the source of colonists. For example, dispersing seeds generally display a leptokurtic distribution, with most falling near the parents and some traveling long distances (Okubo 1980). Most plumed milkweed (Asclepias spp.) seeds blowing more-or-less horizontally across a mowed lawn will be stopped by fragments of taller old-field vegetation in relation to the linear dimensions of the fragments. However, the small proportion of seeds that rise on convection currents and are deposited far from the source by a rainstorm will fall out randomly onto fragments of old field. Thus seeds dispersing near the source will correspond to Fig. 1A, resulting in lower densities in large fragments, whereas those dispersing longer distances in the aerial plankton would be expected to show no density relationship (Fig. 2A).

Dispersal behaviors that produce aggregations through conspecific attraction can result in a positive relationship between patch size and density (Figs. 1D or 2D). Several vertebrate species, including some lizards, birds, and mammals have been shown to use the presence, and possibly the number, of other conspecific animals to indicate the suitability of patches and to direct their movement toward patches (reviewed by Smith and Peacock 1990). For example, the Florida Scrub Jay (Aphelocoma coerulescens) is unlikely to become established in unoccupied, although otherwise suitable, habitat (Stith et al. 1996). Similarly, some species of bark beetle orient to the presence of conspecifics (Birch 1984). If larger patches are more likely to be occupied (due to lower extinction probabilities), this could result in an increase in population size that is disproportional to the increase in patch area (i.e., a positive relationship between density and area).

\section{CONTEXT AND CONCLUSIONS}

If birth, death, or emigration rates vary strongly with patch size, then we would expect the relationship between immigration and patch size to become obscured. Birth and death rates that vary with patch size can be broadly considered as edge effects. Where edge effects are positive (increased birth or decreased death rates at edges), we would expect a negative relationship between patch size and population density. For example, Bowers et al. (1996) found higher pregnancy rates in meadow voles (Microtus pennsylvanicus) with home ranges encompassing habitat edges, relative to voles in habitat interiors. Where edge effects are negative, we would expect a positive relationship between patch size and population density. Many studies demonstrate lowered nesting success (due to increased nest predation) of songbirds along forest edges (see the review by Hartley and Hunter 1998).

Any relationship between emigration rate and patch size is likely to be negative. Mobile organisms that are likely to colonize and leave several patches in a lifetime may emigrate more readily from smaller patches if emigration is triggered by encountering a patch edge (Kareiva 1985), and this process would lead to higher emigration rates in small patches. Similarly, Bevers and Flather (1999) demonstrated that diffusive dispersal results in higher emigration rates in smaller patches. Thus, we would expect emigration behaviors to produce either no relationship or a positive relationship between patch size and population density.

Our review of dispersal behaviors suggests that, when immigration is the dominant process affecting population density in a habitat patch, many species should exhibit population densities that either decrease or at least do not increase with increasing patch size. Immigration should be a dominant process for species that do not exhibit strong edge effects and have low emigration rates. Further, we suggest that immigration will dominate in studies in which population densities are sampled following habitat removal, such as in short-term habitat fragmentation experiments. The effect of individuals dispersing from newly created matrix into remnant habitat patches (e.g., concussion effects; Hagan et al. 1996) will dominate the relationship between patch size and density for some period of time until other processes (edge effects and emigration) become important. The duration of this period will be dependent on the generation time of the species being studied.

To summarize, in many studies of habitat fragmentation, authors express surprise at finding an inverse relationship between patch size and population density. We have demonstrated that the expectation of lower population density in smaller patches often is not reasonable. The appropriate expectation will depend on immigration behavior, edge effects, emigration, and time since fragmentation.

Responses to this article can be read online at: http://www.consecol.org/vol6/issl/art9/responses/index.html. 


\section{Acknowledgments:}

This work is the result of a Friday lunch discussion with members of Carleton University's Landscape Ecology lab. We thank lab members for their strong contribution. Helpful suggestions from anonymous reviewers improved the quality of the manuscript. N. Cappuccino and L. Fahrig received support from Canada's Natural Sciences and Engineering Research Council (NSERC). J. Bowman received support from a Premier's Research Excellence Award to L. Fahrig, and from the Wildlife Research and Development Section of the OMNR.

\section{LITERATURE CITED}

Andrén, H. 1994. Effects of habitat fragmentation on birds and mammals in landscapes with different proportions of suitable habitat: a review. Oikos 71:355-366.

Bender, D. J., T. A. Contreras, and L. Fahrig. 1998. Habitat loss and population decline: a meta-analysis of the patch size effect. Ecology 79:517-533.

Benitez-Malvido, J. 1998. Impact of forest fragmentation on seedling abundance in a tropical rain forest. Conservation Biology 12:380-389.

Bevers, M., and C. H. Flather. 1999. Numerically exploring habitat fragmentation effects on population density using cell-based coupled map lattices. Theoretical Population Biology 55:61-76.

Bierregaard, R. O., Jr., T. E. Lovejoy, V. Kapos, A. A. dos Santos, and R. W. Hutchings. 1992. The biological dynamics of tropical forest fragments: a prospective comparison of fragments and continuous forest. BioScience 42:859-866.

Birch, M. 1984. Aggregation in bark beetles. Pages 331353 in W. Bell and R. Carde, editors. Chemical ecology of insects. Chapman and Hall, New York, New York, USA.

Bowers, M. A., K. Gregario, C. J. Brame, S. F. Matter, and J. L. Dooley, Jr. 1996. Use of space and habitats by meadow voles at home range, patch and landscape scales. Oecologia 105:107-115.

Bowers, M. A., and S. F. Matter. 1997. Landscape ecology of mammals: relationships between density and patch size. Journal of Mammalogy 78:999-1013.

Connor, E. F., A. C. Courtney, and J. M. Yoder. 2000. Individuals-area relationships: the relationship between animal population density and area. Ecology 81:734-748.

Connor, E. F., S. H. Faeth, and D. Simberloff. 1983.
Leafminers on oak: the role of immigration and in situ reproductive recruitment. Ecology 64:191-204.

Debinski, D. M., and R. D. Holt. 2000. A survey and overview of habitat fragmentation experiments. Conservation Biology 14:342-355.

Dooley, J. L., Jr., and M. A. Bowers. 1998. Demographic responses to habitat fragmentation: Experimental tests at the landscape and patch scale. Ecology 79:969-980.

Fahrig, L., and J. E. Paloheimo. 1987. Interpatch dispersal of the cabbage butterfly. Canadian Journal of Zoology 65:616-622.

Fahrig, L., and J. E. Paloheimo. 1988. Determinants of local population size in patchy habitats. Theoretical Population Biology 34:194-213.

Fahrig, L., and G. Merriam. 1985. Habitat patch connectivity and population survival. Ecology 66:17621768 .

Foster, J., and M. S. Gaines. 1991. The effects of a successional habitat mosaic on a small mammal community. Ecology 72:1358-1373.

Gillespie, R. G. 1987. The mechanism of habitat selection in the long-jawed orb-weaving spider Tetragnatha elongata (Araneae, Tetragnathidae). Journal of Arachnology 15:8190 .

Greenbank, D. O., G. W. Schaefer, and R. C. Rainey. 1980. Spruce budworm (Lepidoptera: Tortricidae) moth flight and dispersal: new understanding from canopy observations, radar, and aircraft. Memoirs of the Entomological Society of Canada 110:1-49.

Hagan, J. M., W. M. Vander Haegen, and P. S. McKinley. 1996. The early development of forest fragmentation effects on birds. Conservation Biology 10:188-202.

Hartley, M. J., and M. L. Hunter, Jr. 1998. A metaanalysis of forest cover, edge effects, and artificial nest predation rates. Conservation Biology 12:465-469.

Hawkes, C. 1974. Dispersal of adult cabbage root fly (Erioischia brassicae) in relation to a brassica crop. Journal of Applied Ecology 11:83-93.

Holt, R. D., G. R. Robinson, and M. S. Gaines. 1995. Vegetation dynamics in an experimentally fragmented landscape. Ecology 76:1610-1624.

Kareiva, P. 1985. Finding and losing host plants by Phyllotreta: patch size and surrounding habitat. Ecology 66:1809-1816.

MacArthur, R. H., and E. O. Wilson.1967. The theory of island biogeography. Princeton University Press, Princeton, New Jersey, USA. 
Matlack, G. R. 1989. Secondary dispersal of seeds across snow in Betula lenta, a gap-colonizing tree species. Journal of Ecology 77:853-869.

Moericke, V., R. J. Prokopy, S. Berlocher, and G. L. Bush. 1975. Visual stimuli eliciting attraction of Rhagoletis pomonella flies to trees. Entomologia Experimentalis et Applicata 18:497-507.

Okubo, A. 1980. Diffusion and ecological problems: mathematical models. Springer-Verlag, Berlin, Germany.

Prokopy, R. J., and E. D. Owens. 1983. Visual detection of plants by herbivorous insects. Annual Review of Entomology 28:337-364.

Rey, J. R., and D. R. S. J. Strong. 1983. Immigration and extinction of salt marsh arthropods on islands: an experimental study. Oikos 41:396-401.

Richter, C. J. J. 1970. Aerial dispersal in relation to habitat in eight wolf spider species (Pardosa, Araneae, Lycosidae). Oecologia 5:200-214.

Root, R. B. 1973. Organization of a plant-arthropod association in simple and diverse habitats: the fauna of collards (Brassica oleracea). Ecological Monographs 45:95-120.

Russell, R. W. 1999. Precipitation scrubbing of aerial plankton: inferences from bird behaviour. Oecologia 118:381-387.

Schmiegelow, F. K. A., C. S. Machtans, and S. J. Hannon. 1997. Are boreal birds resilient to forest fragmentation? An experimental study of short-term community responses. Ecology 78:1914-1932.

Schoener, T. W. 1986. Patterns in terrestrial vertebrate versus arthropod communities: do systematic differences in regularity exist? Pages 556-586 in J. Diamond and T. J. Case, editors. Community ecology. Harper and Row, New York, New York, USA.

Smith, A. T., and M. M. Peacock. 1990. Conspecific attraction and the determination of metapopulation colonization rates. Conservation Biology 4:320-323.

Stith, B. M., J. W. Fitzpatrick, G. E. Woolfenden, and B. Pranty. 1996. Classification and conservation of metapopulations: a case study of the Florida scrub jay. Pages 187-215 in D. R. McCullough, editor. Metapopulations and wildlife conservation. Island Press, Washington, D.C., USA.

Venier, L. A., and L. Fahrig. 1996. Habitat availability causes the species-abundance distribution relationship. Oikos 76:564-570.

Yao, J., R. D. Holt, P.M. Rich, W. S. Marshall. 1999. Woody plant colonization in an experimentally fragmented landscape. Ecography 22:715-728. 